\title{
Validity of New Risk Model (McNamara et al., 2016) in Predicting In-Hospital Mortality in Patients with Acute Myocardial Infarction
}

A.A.Mohamed, A.I.Atia, A.H.El-Barbary and M.A.Elian

Department of Cardiology, Faculty of Medicine, Benha University, Benha, Egypt.

Email: dr.ahmd.elbarbary@gmail.com

\begin{abstract}
Foundation: Myocardial dead tissue (MI) because of coronary supply route infection is a main source of death in the United States. Mortality from cardiovascular illness has diminished significantly in the course of recent many years. Many danger models of in-emergency clinic mortality have been produced for patients with AMI. Nonetheless, proceeded with progress in AMI care orders occasional updates to the danger models so clinics can survey their quality as contemporary consideration keeps on advancing. Destinations: To test legitimacy of another patient-level clinical danger model of in emergency clinic mortality for patients with intense myocardial localized necrosis. Patients and strategies: This crosssectional investigation was led on 600 specific patients with intense myocardial dead tissue. All patients were exposed to history taking, full clinical assessment, electrocardiogram, echocardiography, routine research center examinations, cardiovascular troponin and other biomarkers accessible for AMI analysis. Results: The similar examination between patients with mortality and patients without mortality showed factual huge contrasts in regards to creatinine freedom, creatinine and ongoing renal disappointment and measurable high huge contrasts in regards to add up to score, systolic pulse, diastolic circulatory strain, pulse, troponin, capture and stun. There was genuinely a high critical connection between all out score and real mortality. End: The contrasts between clinics help to clarify the variety in the individual likelihood of passing on from AMI. The sort of medical clinic, the arrangement of care by a cardiology administration, and the exhibition of a percutaneous coronary intercession are factors that are freely and essentially connected with the endurance of AMI patients.
\end{abstract}

Keywords: Acute myocardial infarction, Mortality.

\section{Introduction}

Myocardial localized necrosis (MI) because of coronary course illness is a main source of death in the United States, where more than 1 million individuals have intense myocardial areas of dead tissue (AMIs) each year [1]. Around the world, about 8.6 million myocardial areas of localized necrosis happened in 2013 [2].

In the created world, the danger of death in the individuals who have had a ST fragment rise MI is about $10 \%$ [3].

Utilizing factors accessible in the trauma center, individuals with a higher danger of unfriendly result can be recognized. One investigation discovered $0.4 \%$ of patients with a generally safe profile kicked the bucket following 90 days, while in high-hazard individuals it was $21.1 \%$ [4].

Some danger factors for death incorporate age, hemodynamic boundaries (like cardiovascular breakdown, heart failure on affirmation, systolic circulatory strain, or Killip class of two or more noteworthy), ST-fragment deviation, diabetes, serum creatinine, fringe vascular infection, and rise of heart markers [4].

Mortality from cardiovascular illness has diminished significantly in the course of the last not many decades [5], to a limited extent on account of enhancements in intense myocardial localized necrosis (AMI) management [6].

In-emergency clinic mortality has diminished from $29 \%$ in 1969 [7] to <7\% (8). Be that as it may, in excess of 100,000 individuals keep on dying after AMIs in the United States each year [5], and in-emergency clinic mortality shifts generously across hospitals [8], proposing a chance for development. Change for the variety in persistent danger across medical clinics is crucial for empower a more precise evaluation of every medical clinic's presentation and freedom to improve.

Many danger models of in-medical clinic mortality have been produced for patients with AMI. In any case, proceeded with progress in AMI care commands intermittent updates to the danger models so clinics can evaluate their quality as contemporary consideration proceeds to evolve [9].

Anew danger model was created utilizing information from the ACTION (Acute Coronary Treatment and Intervention Outcomes Network) Registry-GWTG (Get With the Guidelines), which included patients from in excess of 300 medical clinics from January 2012 through December 2013.Observed death rates shifted considerably across hazard gatherings, going from $0.4 \%$ in the most reduced danger gathering (score <30) to $49.5 \%$ in the most noteworthy danger gathering (score >59). Age, pulse, systolic circulatory strain, introduction after heart failure, introduction in cardiogenic stun, introduction in cardiovascular breakdown, introduction with ST-fragment height myocardial dead tissue, creatinine freedom, and troponin proportion were all autonomously connected with inemergency clinic mortality [10].

The point of this examination is to test legitimacy of another patient-level clinical danger model of in clinic mortality for patients with intense myocardial localized necrosis so medical clinics can evaluate their quality as contemporary consideration keeps on advancing. 


\section{Patients and Methods}

This cross-sectional investigation was directed on 600 specific patients with intense myocardial dead tissue alluded to Cardiology Department, El-agouza police Hospital.

\section{I-Inclusion criteria}

- Any patient presented to the hospital and diagnosed as acute myocardial infarction, either ST-segment elevation myocardial infarction (STEMI) or non-STsegment elevation myocardial infarction (NSTEMI).

- Patient must present to the hospital within 1 day of onset of symptoms.

- All age groups and both sexes are included.

\section{II-Exclusion criteria}

- Patients transferred out of the hospital before receiving full course of treatment.

- Patients presented to the hospital after 1 day of onset of symptoms.

\subsection{Methods}

\subsection{History taking}

- Personal history: Age, sex, occupation and residence.

- History of any symptoms suggestive of coronary artery diseases such as chest pain with effort.

- Present medical history with special emphasis on: age, gender, current smoking, family history of coronary artery disease, diabetes mellitus, hypertension, hypercholesterolemia, history of prior myocardial infarction or coronary artery bypass graft surgery.

- Past medical history of chronic diseases.

\subsection{Presenting features:}

Pre-hospital, in-hospital, and hospital discharge therapy; timing of treatments; laboratory tests; procedures; and in-hospital outcomes. Mortality was defined as all-cause mortality during hospitalization.

\subsection{Full clinical examination \\ - General examination}

- Vital signs (heart rate and blood pressure) were determined at the time of first medical presentation.

- Each patient was examined searching for any sign of decompensation such as congested neck veins, lower limb oedema or lung crackles.

- Local examination

Inspection, palpation and auscultation were done for every patient.

\subsection{Twelve leads surface Electrocardiogram (ECG)}

Routine 12-lead ECG was done for the patients to detect changes suggestive of myocardial infarction and type of it.

\subsection{Echocardiography}

The examination was carried out according to the recommendation of the American Society of Echocardiography. We used the commercially available GE Vivid 7 machine which was equipped with Doppler tissue imaging mode.

Echo was used to assess the possibility of CAD and myocardial infarction. M-mode, two-dimensional and Doppler echocardiographic assessment were done for all patients.

\subsection{Routine laboratory investigations}

They were done with particular attention to complete blood picture, urea, creatinine and random blood glucose level (baseline creatinine clearance was estimated using the Cockcroft-Gault formula).

\subsection{Cardiac troponin and other biomarkers available for AMI diagnosis}

Including creatine kinase $(\mathrm{CK})$ and its myocardial band fraction (CK-MB) (baseline troponin ratio was defined as the baseline troponin value divided by the local laboratory-specific upper limit of normal). This approach has been used previously to investigate the association of maximum troponin ratio with outcomes.

This risk model score based on a variety of data obtained from in-hospital patients presented by acute myocardial infarction. These data include age, heart rate, systolic blood pressure (SBP), presentation with STsegment elevation myocardial infarction (STEMI), presentation in heart failure, presentation after cardiac arrest, presentation in cardiogenic shock, creatinine clearance $(\mathrm{CrCl})$ and troponin ratio.

\subsection{Statistical analysis}

Data were coded and entered using the statistical package SPSS (Statistical Package for the Social Sciences) version 25. Data was summarized using mean, standard deviation, median, minimum and maximum in quantitative data and using frequency (count) and relative frequency (percentage) for categorical data. Comparisons between quantitative variables were done using the non-parametric Mann-Whitney test. For comparing categorical data, Chi square $(\chi 2)$ test was performed. Exact test was used instead when the expected frequency is less than 5.

ROC curve was constructed with area under curve analysis performed to detect best cutoff value of score for detection of mortality. P-values less than 0.05 were considered as statistically significant.

\section{Results}

As regard total score, the mean total score of the patients was $34.43 \pm 10.6$. As regard age, the mean age of the patients was $66.71 \pm 9.63$ years. As regard blood pressure of the patients, the mean systolic blood pressure was $141.58 \pm 27.87 \mathrm{mmHg}$ and the mean diastolic blood pressure was $79.4 \pm 17.64 \mathrm{mmHg}$. As regard weight, the mean weight of the patients was $90.99 \pm 13.31 \mathrm{~kg}$. As regard creatinine clearance, the mean creatinine 
clearance of the patients was $78.03 \pm 25.73$. As regard creatinine, the mean creatinine of the patients was $1.24 \pm$ 0.43 . As regard heart rate, the mean heart rate of the patients was $93 \pm 21.17$. As regard troponin, the mean troponin of the patients was $11.53 \pm 9.37$ table (1).

The observed patients with total scores $<30,30$ to 39,40 to 49,50 to 59 , and $>59$ were $39 \%, 33.5 \%, 21 \%$, $2.5 \%$ and $4 \%$, respectively (figure 1 ).

The observed mortality in patients with risk scores $<50,50$ to 59 and $>59$ were $0.0 \%, 20 \%$ and $100 \%$ respectively.

As regard mortality, of the six hundred patients, 191 (95.5\%) had no mortality and $9(4.5 \%)$ had a mortality. As regard arrest, of the six hundred patients, $194(97 \%)$ were not arrested and $6(3 \%)$ were arrested. As regard shock, of the six hundred patients, 191 $(95.5 \%)$ were not shocked and $9(4.5 \%)$ were shocked. As regard heart failure, of the six hundred patients, 170 $(85 \%)$ had no heart failure and $30(15 \%)$ had heart failure. As regard STEMI, of the six hundred patients, $122(61 \%)$ had no STEMI and $78(39 \%)$ had STEMI. As regard sex, of the six hundred patients, $65(32.5 \%)$ were females and $135(67.5 \%)$ were males table (2).
As regard diabetes mellitus, of the six hundred patients, 129 (64.5\%) were non-diabetic and 71 (35.5\%) were diabetic. As regard hypertension, 50 (25\%) were non-hypertensive and $150(75 \%)$ were hypertensive. As regard smoking, $120(60 \%)$ were non-smokers and 80 $(40 \%)$ were smokers table (2).

The comparative study between patients who survived and patients who died show statistically significant differences regarding age, STEMI, heart failure and creatinine clearance $(\mathrm{p}<0.05)$ and statistical high significant differences regarding systolic blood pressure, heart rate, troponin, cardiac arrest, cardiogenic shock and total score $(\mathrm{p}<0.001)$.

Studying of other variables show statistically significant differences regarding weight, diabetes mellitus, atrial fibrillation and Cerebrovascular stroke ( $\mathrm{p}$ $<0.05)$ and statistical high significant differences regarding diastolic blood pressure, T-wave inversion, current renal dialysis and creatinine $(\mathrm{p}<0.001)$.

Table (6) showed statistically a high significant relation between total score and actual mortality ( $\mathrm{p}<$ $0.001)$.

Table (1) Description of all studied patients.

\begin{tabular}{lccccc}
\hline & Mean & Standard Deviation & Median & Minimum & Maximum \\
\hline total score & 34.43 & 10.60 & 33.00 & 15.00 & 71.00 \\
age & 66.71 & 9.63 & 67.50 & 39.00 & 89.00 \\
SBP & 141.58 & 27.87 & 145.00 & 70.00 & 220.00 \\
DBP & 79.40 & 17.64 & 80.00 & 20.00 & 120.00 \\
weight & 90.99 & 13.31 & 90.00 & 70.00 & 150.00 \\
creat.cl & 78.03 & 25.73 & 77.33 & 25.02 & 131.94 \\
creat. & 1.24 & 0.43 & 1.12 & 0.69 & 3.20 \\
H.rate & 93.00 & 21.17 & 90.00 & 50.00 & 140.00 \\
troponin & 11.53 & 9.37 & 8.55 & 2.30 & 58.70 \\
\hline
\end{tabular}

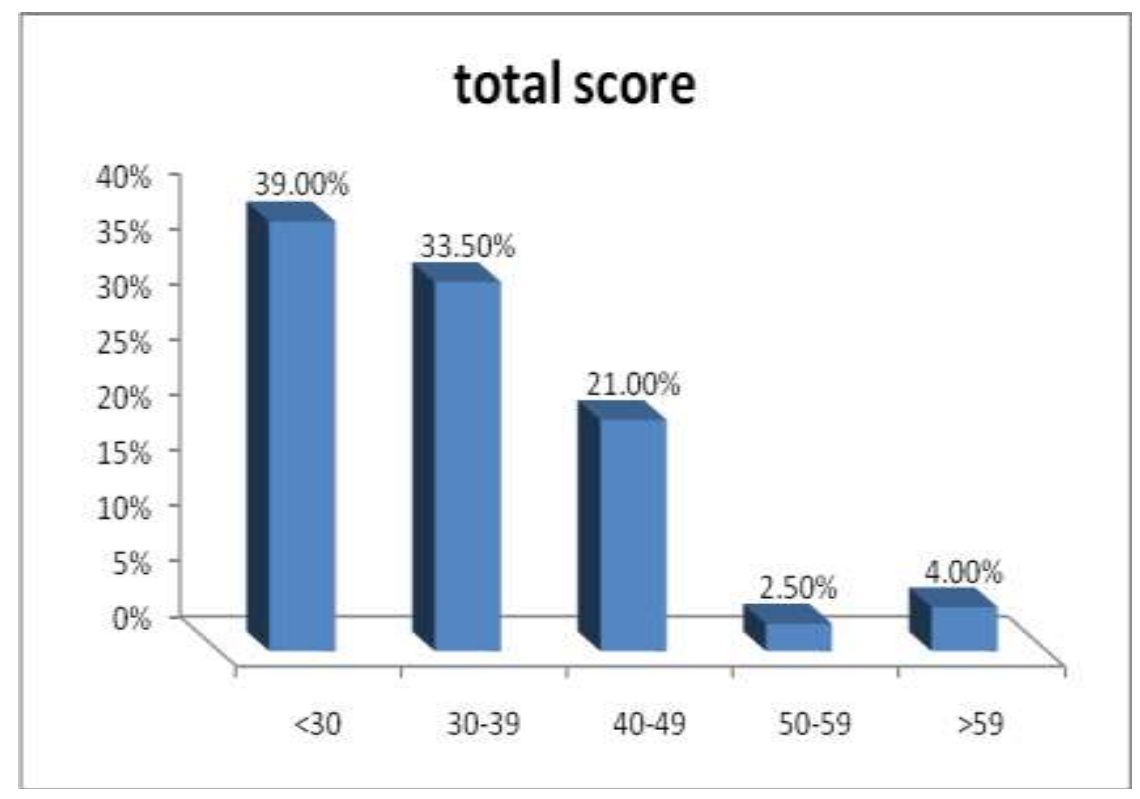

Fig. (1) Total score. 
Table (2) Mortality, medical history and gender.

\begin{tabular}{|c|c|c|c|}
\hline & & Count & $\%$ \\
\hline \multirow{2}{*}{ Mortality } & yes & 9 & $4.5 \%$ \\
\hline & No & 191 & $95.5 \%$ \\
\hline \multirow{2}{*}{ arrest } & yes & 6 & $3.0 \%$ \\
\hline & No & 194 & $97.0 \%$ \\
\hline \multirow{2}{*}{ shock } & yes & 9 & $4.5 \%$ \\
\hline & No & 191 & $95.5 \%$ \\
\hline \multirow{2}{*}{ H. failure } & yes & 30 & $15.0 \%$ \\
\hline & No & 170 & $85.0 \%$ \\
\hline \multirow{2}{*}{ STEMI } & yes & 78 & $39.0 \%$ \\
\hline & No & 122 & $61.0 \%$ \\
\hline \multirow{2}{*}{ Gender } & Male & 135 & $67.5 \%$ \\
\hline & Female & 65 & $32.5 \%$ \\
\hline \multirow{2}{*}{ DM } & yes & 71 & $35.5 \%$ \\
\hline & No & 129 & $64.5 \%$ \\
\hline \multirow{2}{*}{ HTN } & yes & 150 & $75.0 \%$ \\
\hline & No & 50 & $25.0 \%$ \\
\hline \multirow{2}{*}{ Smoker } & yes & 80 & $40.0 \%$ \\
\hline & No & 120 & $60.0 \%$ \\
\hline
\end{tabular}

Table (3) Relation of mortality with baseline characteristics.

\begin{tabular}{lccccccccccc}
\hline & \multicolumn{9}{c}{ yes } & \multicolumn{9}{c}{ Mortality } & \multicolumn{3}{c}{ No } & P value \\
\hline & Mean & $\begin{array}{l}\text { Standard } \\
\text { Deviation }\end{array}$ & Median & Minimum & Maximum & Mean & $\begin{array}{c}\text { Standard } \\
\text { Deviation }\end{array}$ & Median & Minimum & Maximum \\
total & & & & & & & & & & & \\
score & 63.33 & 5.41 & 62.00 & 54.00 & 71.00 & 33.06 & 8.66 & 32.00 & 15.00 & 57.00 & $<0.001$ \\
age & 70.22 & 7.55 & 70.00 & 55.00 & 81.00 & 66.54 & 9.70 & 67.00 & 39.00 & 89.00 & 0.209 \\
SBP & 91.11 & 14.53 & 90.00 & 70.00 & 120.00 & 143.95 & 26.04 & 150.00 & 80.00 & 220.00 & $<0.001$ \\
DBP & 51.11 & 10.54 & 50.00 & 40.00 & 70.00 & 80.73 & 16.78 & 80.00 & 20.00 & 120.00 & $<0.001$ \\
weight & 84.44 & 5.83 & 85.00 & 75.00 & 90.00 & 91.30 & 13.50 & 90.00 & 70.00 & 150.00 & 0.134 \\
creat.cl & 49.54 & 17.67 & 44.19 & 25.82 & 73.75 & 79.11 & 25.40 & 78.41 & 25.02 & 131.94 & 0.004 \\
creat. & 1.87 & 0.76 & 1.82 & 1.00 & 3.20 & 1.22 & 0.40 & 1.10 & 0.69 & 2.98 & 0.007 \\
H.rate & 121.11 & 19.81 & 125.00 & 75.00 & 140.00 & 91.68 & 20.34 & 90.00 & 50.00 & 140.00 & $<0.001$ \\
troponin & 25.39 & 15.42 & 16.80 & 7.60 & 52.30 & 10.87 & 8.51 & 8.40 & 2.30 & 58.70 & $<0.001$ \\
\hline
\end{tabular}

Table (4) Relation of mortality with medical history and gender.

\begin{tabular}{|c|c|c|c|c|c|c|}
\hline & & \multicolumn{4}{|c|}{ Mortality } & \multirow{3}{*}{$P$ value } \\
\hline & & \multicolumn{2}{|c|}{ Yes } & \multicolumn{2}{|c|}{ No } & \\
\hline & & Count & $\%$ & Count & $\%$ & \\
\hline \multirow{2}{*}{ arrest } & yes & 3 & $33.3 \%$ & 3 & $1.6 \%$ & \multirow{2}{*}{0.001} \\
\hline & No & 6 & $66.7 \%$ & 188 & $98.4 \%$ & \\
\hline \multirow{2}{*}{ shock } & yes & 4 & $44.4 \%$ & 5 & $2.6 \%$ & \multirow{2}{*}{$<0.001$} \\
\hline & No & 5 & $55.6 \%$ & 186 & $97.4 \%$ & \\
\hline \multirow{2}{*}{ H.failure } & yes & 3 & $33.3 \%$ & 27 & $14.1 \%$ & \multirow{2}{*}{0.136} \\
\hline & No & 6 & $66.7 \%$ & 164 & $85.9 \%$ & \\
\hline \multirow{2}{*}{ STEMI } & yes & 5 & $55.6 \%$ & 73 & $38.2 \%$ & \multirow{2}{*}{0.316} \\
\hline & No & 4 & $44.4 \%$ & 118 & $61.8 \%$ & \\
\hline \multirow{2}{*}{ Gender } & Male & 5 & $55.6 \%$ & 130 & $68.1 \%$ & \multirow{2}{*}{0.476} \\
\hline & Female & 4 & $44.4 \%$ & 61 & $31.9 \%$ & \\
\hline \multirow{2}{*}{ DM } & yes & 5 & $55.6 \%$ & 66 & $34.6 \%$ & \multirow{2}{*}{0.285} \\
\hline & No & 4 & $44.4 \%$ & 125 & $65.4 \%$ & \\
\hline \multirow{2}{*}{ HTN } & yes & 7 & $77.8 \%$ & 143 & $74.9 \%$ & \multirow{2}{*}{1} \\
\hline & No & 2 & $22.2 \%$ & 48 & $25.1 \%$ & \\
\hline \multirow{2}{*}{ Smoker } & yes & 5 & $55.6 \%$ & 75 & $39.3 \%$ & \multirow{2}{*}{0.488} \\
\hline & No & 4 & $44.4 \%$ & 116 & $60.7 \%$ & \\
\hline
\end{tabular}


Table (5) Relation between mortality and other variables.

\begin{tabular}{|c|c|c|c|c|c|c|}
\hline & \multicolumn{6}{|c|}{ Mortality } \\
\hline & & \multicolumn{2}{|c|}{ Yes } & \multicolumn{2}{|c|}{ No } & \multirow{2}{*}{$P$ value } \\
\hline & & Count & $\%$ & Count & $\%$ & \\
\hline \multirow{2}{*}{ prev.MI } & yes & 3 & $33.3 \%$ & 43 & $22.5 \%$ & \multirow[b]{2}{*}{0.432} \\
\hline & No & 6 & $66.7 \%$ & 148 & $77.5 \%$ & \\
\hline \multirow{2}{*}{ prev.PCI } & yes & 3 & $33.3 \%$ & 43 & $22.5 \%$ & \multirow{2}{*}{0.432} \\
\hline & No & 6 & $66.7 \%$ & 148 & $77.5 \%$ & \\
\hline \multirow{2}{*}{ post HF } & yes & 2 & $22.2 \%$ & 25 & $13.1 \%$ & \multirow{2}{*}{0.349} \\
\hline & No & 7 & $77.8 \%$ & 166 & $86.9 \%$ & \\
\hline \multirow{2}{*}{ post CABG } & yes & 1 & $11.1 \%$ & 29 & $15.2 \%$ & \multirow{2}{*}{1} \\
\hline & No & 8 & $88.9 \%$ & 162 & $84.8 \%$ & \\
\hline \multirow{2}{*}{ DLP } & yes & 6 & $66.7 \%$ & 120 & $62.8 \%$ & \multirow[b]{2}{*}{1} \\
\hline & No & 3 & $33.3 \%$ & 71 & $37.2 \%$ & \\
\hline \multirow{2}{*}{ Ch.lung dis } & yes & 2 & $22.2 \%$ & 27 & $14.1 \%$ & \multirow{2}{*}{0.621} \\
\hline & No & 7 & $77.8 \%$ & 164 & $85.9 \%$ & \\
\hline \multirow{2}{*}{ CRF } & yes & 2 & $22.2 \%$ & 6 & $3.1 \%$ & \multirow{2}{*}{0.044} \\
\hline & No & 7 & $77.8 \%$ & 185 & $96.9 \%$ & \\
\hline \multirow{2}{*}{$\mathbf{A F}$} & yes & 2 & $22.2 \%$ & 18 & $9.4 \%$ & \multirow{2}{*}{0.223} \\
\hline & No & 7 & $77.8 \%$ & 173 & $90.6 \%$ & \\
\hline \multirow{2}{*}{ CVS } & yes & 3 & $33.3 \%$ & 21 & $11.0 \%$ & \multirow{2}{*}{0.079} \\
\hline & No & 6 & $66.7 \%$ & 170 & $89.0 \%$ & \\
\hline \multirow{2}{*}{ PVD } & yes & 2 & $22.2 \%$ & 20 & $10.5 \%$ & \multirow{2}{*}{0.259} \\
\hline & No & 7 & $77.8 \%$ & 171 & $89.5 \%$ & \\
\hline \multirow{2}{*}{ ST.depres } & yes & 2 & $22.2 \%$ & 22 & $11.5 \%$ & \multirow{2}{*}{0.295} \\
\hline & No & 7 & $77.8 \%$ & 169 & $88.5 \%$ & \\
\hline \multirow{2}{*}{$\mathbf{T}$ wave inv } & yes & 3 & $33.3 \%$ & 18 & $9.4 \%$ & \multirow{2}{*}{0.056} \\
\hline & No & 6 & $66.7 \%$ & 173 & $90.6 \%$ & \\
\hline
\end{tabular}

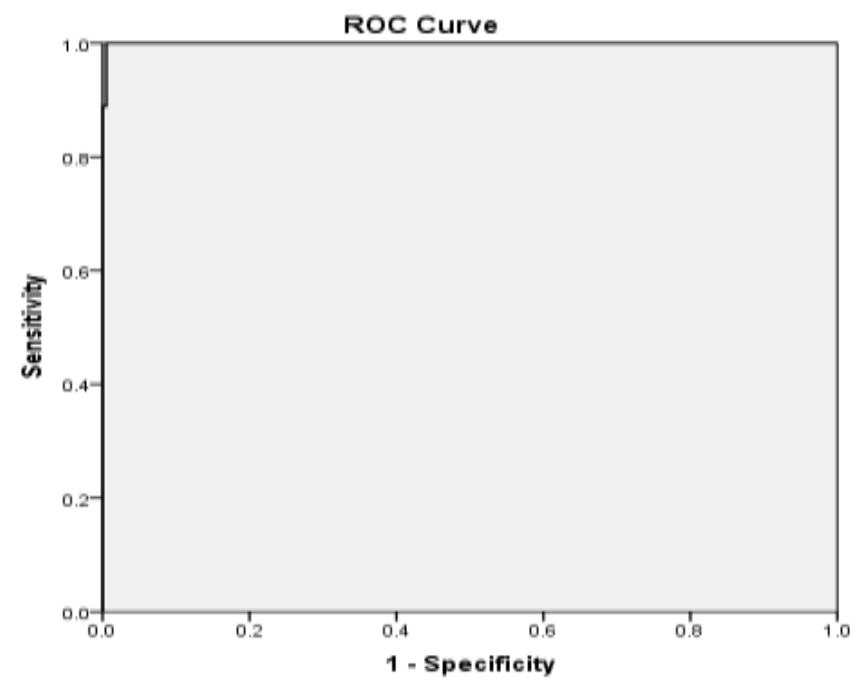

Fig (2): ROC curve for prediction of mortality using score

Table (6): Relation between total score and actual mortality

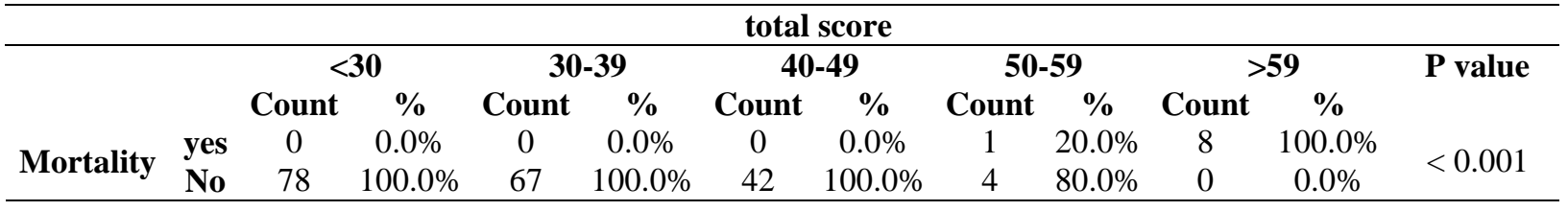




\section{Discussion}

Intense MI can be analyzed if any of the accompanying standards is met. Discovery of an ascent of estimations of cardiovascular biomarkers of rot (ideally heart troponins) with at any rate one worth surpassing the 99th percentile of ordinary sound populace (upper reference limit (URL)) and with in any event one of the accompanying:

a. Symptoms of ischemia.

b. New or assumed new critical ST-fragment - T wave changes or group branch block (LBBB).

c. Development of neurotic $\mathrm{Q}$ waves in the electrocardiogram (ECG).

d. Imaging proof of new loss of reasonable myocardial or new territorial divider movement irregularity.

e. Identification of an intracoronary blood clot by angiography or autopsy (11).

Mortality from cardiovascular illness has diminished drastically in the course of recent many years, partially as a result of upgrades in intense myocardial localized necrosis (AMI) the board. In-clinic mortality has diminished from 29\% in 1969 to $<7 \%$ today. Be that as it may, in excess of 100,000 individuals keep on dieing after AMIs in the United States every year, and in-clinic mortality changes significantly across medical clinics, recommending a chance for development. Change for the variety in persistent danger across clinics is crucial for empower a more precise evaluation of every clinic's exhibition and freedom to improve [12].

In this investigation, we attempted to test legitimacy of another patient-level clinical danger model of in medical clinic mortality for patients with intense myocardial dead tissue so emergency clinics can survey their quality as contemporary consideration keeps on advancing. This examination has included 200 patients introduced by intense myocardial localized necrosis conceded to Cardiology Department, El-agouza police Hospital.

As respect all out score, the mean all out score of the patients was $34.43 \pm 10.6$. As respect age, the mean age of the patients was $66.71 \pm 9.63$ years. As respect circulatory strain of the patients, the mean systolic pulse was $141.58 \pm 27.87 \mathrm{mmHg}$ and the mean diastolic circulatory strain was $79.4 \pm 17.64 \mathrm{mmHg}$. As respect weight, the mean load of the patients was $90.99 \pm 13.31$ $\mathrm{kg}$. As respect creatinine freedom, the mean creatinine leeway of the patients was $78.03 \pm 25.73$. As respect creatinine, the mean creatinine of the patients was $1.24 \pm$ 0.43 . As respect pulse, the mean pulse of the patients was $93 \pm 21.17$. As respect troponin, the mean troponin of the patients was $11.53 \pm 9.37$.

McNamara et al. [10] created and approved a stingy patient-level clinical danger model of in-clinic mortality for contemporary patients with intense myocardial localized necrosis. They noticed no significant contrasts between the 2 gatherings with respect to benchmark attributes.
In our examination we tracked down that the noticed death rates in patients with hazard scores $<50,50$ to 59 and $>59$ were $0.0 \%, 20 \%$ and $100 \%$ respectively.. Of the 600 patients, 191 (95.5\%) had no mortality and 9 $(4.5 \%)$ had a mortality. As respect capture, of the 600 patients, $194(97 \%)$ were not captured and $6(3 \%)$ were captured. As respect stun, of the 600 patients, 191 $(95.5 \%)$ were not stunned and $9(4.5 \%)$ were stunned. As respect cardiovascular breakdown, of the 600 patients, $170(85 \%)$ had no cardiovascular breakdown and 30 (15\%) had cardiovascular breakdown. As respect STEMI, of the 600 patients, $122(61 \%)$ had no STEMI and $78(39 \%)$ had STEMI.

McNamara et al. [10] related 9 factors autonomously with in-emergency clinic mortality: age; introducing pulse and systolic circulatory strain; introduction after heart failure, in cardiogenic stun, in cardiovascular breakdown, and with STEMI; creatinine freedom; and troponin proportion. The noticed death rates in patients with hazard scores $<30,30$ to 39,40 to 49,50 to 59 , and $>59$ were $0.4 \%, 1.7 \%, 5.5 \%, 18.5 \%$, and $49.5 \%$, separately.

The similar investigation between patients who survived and patients who died showed factual huge contrasts in regards to creatinine leeway, creatinine and persistent renal disappointment $(\mathrm{p}<0.05)$ and measurable high huge contrasts in regards to add up to score, systolic pulse, diastolic circulatory strain, pulse, troponin, capture and stun $(\mathrm{p}<0.001)$.

As per ROC bend information of absolute score in this examination, at the ideal cutoff of all out score of 53.5 , zone under the bend is 0.999 , the senstivity is $100 \%$ and the specifiicty is $99.5 \%$. Our examination showed measurably a high huge connection between all out score and genuine mortality $(\mathrm{p}<0.001)$.

The GRACE (Global Registry of Acute Coronary Events) score was created on nonconsecutive patients in select worldwide clinical locales, and the TIMI (Thrombolysis In Myocardial Infarction)(12) and GUSTO (Global Use of Strategies to Open Occluded Arteries) [13] scores were created in clinical preliminary populaces of patients with STEMI or NSTEMI or flimsy angina.

Furthermore, since the formation of these models, critical advances have been made in the conclusion and care of patients with AMI. The new danger model contrasted well and a past hazard model created utilizing ACTION Registry-GWTG information from 2007 and 2008, which has been consequently utilized for quality criticism to partaking clinics. A considerable lot of the information components utilized for hazard change were indistinguishable, including age, introducing systolic pulse, and troponin proportion. Of course the principle contrast in hazard change for the new model was the capacity to incorporate introduction after heart failure, which was not accessible at the time the past model was made. Splines and associations were not, at this point critical, bringing about an easier model for imminent use. Other unpretentious contrasts between the present and past models incorporate the utilization of creatinine 
freedom instead of serum creatinine level (which was less prescient) and the division of cardiovascular breakdown and cardiogenic stun at the hour of introduction, which were both autonomously connected with in-emergency clinic mortality [14].

Heart failure has been demonstrated to be a significant indicator of AMI mortality [15]. The National Cardiovascular Data Registry CathPCI hazard model remembers these patients for the companion, and introduction after heart failure is a significant factor in hazard adjustment [16].

Be that as it may, incorporation of patients with heart failure in mortality correlations in the setting of percutaneous coronary mediation has been questionable, as the models are lacking to completely adapt to the danger for these occasions, given their heterogeneity in clinical seriousness, and consideration of these patients in emergency clinic scorecards for percutaneous coronary intercession can bring about unintended outcomes to retain forceful treatment [17].

Bernal [18] uncovered generous contrasts among locales and between clinics in the administration of patients with AMI.

Bosch et al. [19] announced a lower 28-day death rate among the AMI patients who were conceded to coronary consideration units, and a lower mortality because of AMI 30 days after medical clinic affirmation has been related with the kickoff of a catheterization lab. The likelihood of an AMI patient passing on during the clinic stay has been assessed to be $25 \%$ higher in emergency clinics that don't have an emergency unit.

Ruiz-Nodar et al. [20] tracked down that the treatment got by patients with non-ST height intense coronary disorder conceded to emergency clinics with no catheterization research center contrasted all the more generally from that suggested by the rules; they noticed no huge contrasts in-emergency clinic mortality, yet the occurrence of readmission was essentially higher.

Krumholz et al. [21] analyzed clinic level 30-day riskstandardized death rates (RSMRs) after hospitalization for AMI altogether nonfederal intense consideration medical clinics in the United States, utilizing an approved model that normalizes for contrasts in tolerant danger. The RSMR for patients conceded with AMI showed a checked and critical decline, as did between-medical clinic variety.

Dharmarajan et al. [22] analyzed the connection between clinic 30-day RSMRs for more seasoned patients (matured $\geq 65$ years) and those for more youthful patients (matured 18 to 64 years) and all patients (matured $\geq 18$ years) with AMI. They inferred that clinic mortality rankings for more seasoned patients with AMI conflictingly reflect rankings for more youthful patients. Fuse of more youthful patients into appraisal of medical clinic results would allow further assessment of the presence and impact old enough related quality contrasts.

Asaria et al. [23] showed that basic strategy to lessen mortality after intense myocardial localized necrosis is opportune contact with the wellbeing framework and analysis of the intense myocardial dead tissue. Significant decreases in intense myocardial dead tissue mortality will expect regard for the enormous extent of these passings that are not gone before by a clinic affirmation or are gone before by a confirmation for an another reason.

\section{Study limitations}

A moderately predetermined number of patients were remembered for this investigation, and this was liable for certain outcomes being genuinely non-huge; along these lines, it should be approved tentatively in bigger examinations.

\section{Conclusion}

Scoring system applied in this study is valid and can be used to predict in-hospital mortality of patients with acute myocardial infarction and show a favorable sensitivity and specificity results. Factors that work as highly important predictor of mortality in this study are age, systolic blood pressure, heart rate, presentation with ST segment elevation myocardial infarction, presentation in heart failure, presentation in cardiogenic shock, presentation after cardiac arrest, creatinine clearance, troponin ratio.

\section{References}

[1] W. Rosamond, K. Flegal, G. Friday, K. Furie, A. Go, K. Greenlund, S. Kittner. Heart disease and stroke statistics-2007 update. Circulation. Vol. 115(5), pp. e69-e171, 2007.

[2] T. Vos, R.M. Barber, B. Bell, A. Bertozzi-Villa, S. Biryukov, I. Bolliger, L. Duan. Global, regional, and national incidence, prevalence, and years lived with disability for 301 acute and chronic diseases and injuries in 188 countries, 1990-2013: a systematic analysis for the Global Burden of Disease Study. Vol.386(9995), pp. 743, 2013.

[3] P.G.Steg, S.K.James, D.Atar, L.P.Badano, C. B.Lundqvist, A.M.Borger, A.H.Gershlick. ESC Guidelines for the management of acute myocardial infarction in patients presenting with ST-segment elevation. European Heart Journal. Vol. 33, pp.345 - 445, 2012.

[4] E.L. De Sa, J. Lopez-Sendon, I. Anguera, A. Bethencourt, X. Bosch, Proyecto de Estudio del Pronóstico de la Angina (PEPA). Investigators. Prognostic value of clinical variables at presentation in patients with non-ST-segment elevation acute coronary syndromes: results of the Proyecto de Estudiodel Pronostico de la Angina (PEPA). Medicine. Vol. 81(6), pp. 434-442, 2002.

[5] 5- R.S.Vasan, E.J.Benjamin. The Future of Cardiovascular Epidemiology. Circulation. Vol. 133(25), pp. 2626-2633, 2016.

[6] E. S. Ford, U.A. Ajani, J.B. Croft, J. A. Critchley, D.R. Labarthe, T.E. Kottke, S. Capewell. Explaining the decrease in US deaths from coronary disease, 1980-2000. New England Journal of Medicine. Vol. 356(23), pp. 2388-2398, 2007. 
[7] J.J.de Vreede, A. P.Gorgels, G.M.Verstraaten, F.Vermeer, W.R.Dassen, H.J.Wellens. Did prognosis after acute myocardial infarction change during the past 30 years? A meta-analysis. Journal of the American College of Cardiology. Vol. 18(3), pp. 698-706, 1991.

[8] M.C.Kontos, S.L.Rennyson, A.Y.Chen, K.P.Alexander, E. D.Peterson, M.T.Roe. The association of myocardial infarction process of care measures and in-hospital mortality: a report from the NCDR®. American Heart Journal. Vol. 168(5), pp. 766-775, 2014.

[9] T.C.Johnston, M.D.Coory, I.Scott, S.Duckett. Should we add clinical variables to administrative data?: The case of risk-adjusted case fatality rates after admission for acute myocardial infarction. Medical Care. Vol. 45(12), pp. 1180-1185, 2007.

[10] R.L. McNamara, K.F. Kennedy, D.J. Cohen, D.B. Diercks, M. Moscucci, S. Ramee, J.A. Spertus. Predicting in-hospital mortality in patients with acute myocardial infarction. Journal of the American College of Cardiology. Vol. 68(6), pp. 626-635, 2016.

[11] K.Thygesen, J.S.Alpert, A.S.Jaffe. Third universal definition of myocardial infarction. Circulation. Vol. 126, pp. 20-35, 2012.

[12]D.Mozaffarian, E.J.Benjamin, A.S.Go. American Heart Association Statistics Committee and Stroke Statistics Subcommittee. Heart disease and stroke statistics-2016 update: a report from the American Heart Association. Circulation. Vol. 133, pp. e38-360, 2016.

[13] A.E.Alahmar, C.P.Nelson, K.I.Snell. Resuscitated cardiac arrest and prognosis following myocardial infarction. Heart. Vol. 100, pp. 1125-32, 2014.

[14]C.T.Chin, A.Y.Chen, T.Y.Wang. Risk adjustment for in-hospital mortality of contemporary patients with acute myocardial infarction: the Acute Coronary Treatment and Intervention Outcomes Network (ACTION) Registry-Get With the Guidelines (GWTG) acute myocardial infarction mortality model and risk score. Am Heart J. vol. 161, pp. 113-22, 2011.

[15]J.S.S.G. de Jong, R.F.Marsman, J.P.S.Henriques. Prognosis among survivors of primary ventricular fibrillation in the percutaneous coronary intervention era. Am Heart J. vol.158, pp. 467-72, 2009.
[16] J.M.Brennan, J.P.Curtis, D.Dai. Enhanced mortality risk prediction with a focus on high risk percutaneous coronary intervention: results from $1,208,137$ procedures in the NCDR (National Cardiovascular Data Registry). J Am Coll Cardiol Intv. Vol. 6, pp. 790-9, 2013.

[17]EL.Hannah. The public reporting risk of performing high-risk procedures: Perception or reality. J Am Coll Cardiol Intv. Vol. 8, pp.17-8, 2015.

[18]E.Bernal. Variabilidad en el riesgo de morir por cardiopat1'a isque'mica en hospitales del Sistema Nacional de Salud. Documento de trabajo vol.1, pp. 336, 2007.

[19]D.Bosch, R.Masia', J.Sala, J.Vila, R.Ramos, R.Elosua. Impacto de la apertura de un nuevo laboratorio de hemodina'mica sobre la supervivencia a 30 días y a 2 años en los pacientes con infarto de miocardio. Rev Esp Cardiol. Vol. 64, pp. 96-104, 2011.

[20] J.R. Ruiz-Nodar, A. Cequier, T. Lozano, F. Ferna'ndez, I. Mo“ 1ler, S. Aba'n. Impacto del tipo de hospital en el tratamiento y evolución de los pacientes con si'ndrome coronario agudo sin elevación del ST. Rev Esp Cardiol. Vol. 63, pp. 390-9, 2010.

[21] H.M. Krumholz, Y. Wang, J. Chen, E.E. Drye, J.A. Spertus, J.S. Ross, J.P. Curtis, B.K. Nallamothu, J.H. Lichtman, E.P. Havranek, F.A. Masoudi, M.J. Radford, L.F. Han, M.T. Rapp, B.M. Straube, S.T. Normand. Reduction in acute myocardial infarction mortality in the United States: Risk-standardized mortality rates from 1995-2006. JAMA; vol.302(7), pp. 767-773, 2009.

[22] K.Dharmarajan, McNamara RL, Wang Y, Masoudi FA, Ross JS, Spatz EE, Desai NR, de Lemos JA, Fonarow GC, Heidenreich PA, Bhatt DL, Bernheim SM, Slattery LE, Khan YM and Curtis JP. Age differences in hospital mortality for acute myocardial infarction: Implications for hospital profiling. Ann Intern Med. Vol. 167(8),pp. 555564, 2017.

[23]P.Asaria, P.Elliott, M.Douglass, Z.Obermeyer, M.Soljak, A.Majeed, M.Ezzati. Acute myocardial infarction hospital admissions and deaths in England: A national follow-back and followforward record-linkage study. Lancet Public Health. Vol. 2, pp. 191-201, 2017. 